\title{
Design de serviço colaborativo e relacional de incentivo a prática de atividades físicas a partir da metodologia HCD
}

Design of a relational and collaborative service to motivate the practice of physical activities based on the HCD methodology

FREITAS, Mariana Ferreira de; Mestranda; ESDI/UERJ

mariana7freitas@gmail.com

PERNES, Fernanda Gusmão; Mestranda; PPG Design/PUC-Rio

fernandagusmaopernes@gmail.com

CIPOLLA, Carla; Doutora em Design pelo Politécnico de Milão; Professora na Coppe/UFRJ

carla.cipolla@ufrj.br

\section{Resumo}

Este artigo descreve o desenvolvimento de uma proposta conceitual de serviço a partir do método Human-centered Design (HCD Design). O serviço RAD visa incentivar a prática de exercícios físicos introduzindo momentos de lazer e descontração a grupos pré-formados, como equipes de trabalho, associações de moradores e clubes de terceira idade. Através de plataformas habilitantes, os integrantes escolhem colaborativamente microatividades para formar a rotina a ser desempenhada na semana. A matriz de serviços colaborativos e relacionais foi empregada para observar as gradações destes conceitos nas diferentes fases do serviço, desde a sua introdução ao grupo até a execução autônoma. Entende-se que o RAD é um sistema produto-serviço de caráter colaborativo e relacional que habilita os usuários a construírem o hábito de praticar atividades físicas suprindo dificuldades como a falta de local adequado, companhia e tempo na rotina diária.

Palavras Chave: design de serviços; serviços colaborativos relacionais; atividades físicas e comunidade.

\begin{abstract}
This article describes the development of a conceptual proposal for a service from the Humancentered Design (HCD Design) method. The RAD service aims to encourage the practice of physical exercises by introducing moments of leisure and relaxation to pre-formed groups, such as work teams, neighbourhood associations and senior citizens' clubs. Through enabling platforms, members collaboratively choose micro activities to form the routine to be performed on the week. The matrix of collaborative and relational services was used to observe the gradations of these concepts in the different phases of the service, from its introduction to the group to the autonomous execution. RAD is understood to be a collaborative and relational product-service system that enables users to build a habit of practising physical activities, such as lack of adequate space, companionship and time in daily routine.
\end{abstract}

Keywords: service design; collaborative and relational services; physical activities and community. 


\section{Introdução}

O conforto proporcionado pelas máquinas no mundo moderno gera um sedentarismo generalizado, o que ocasiona problemas de saúde a longo prazo, como dores na coluna e nas articulações, obesidade, falta de força muscular e doenças cardiovasculares. Para combater o sedentarismo é necessário o desenvolvimento do hábito de praticar exercícios físicos.

A criação do hábito exige esforço e comprometimento. Manter a frequência dos exercícios é importante para que a pessoa consolide a nova prática a sua vida diária. A falta de motivação impede que as pessoas mantenham a frequência necessária, fazendo com que parem e recomecem constantemente a tentativa da criação do hábito.

A hipótese é que fatores externos contribuem para a não permanência do hábito, por exemplo, não ter local específico para a prática de exercícios físicos, não ter companhia e ter uma rotina diária desestruturada. Logo, constatou-se o seguinte desafio de design: Como criar um serviço que reúna pessoas em grupos durante a semana para a prática de atividades físicas em prol de prevenir doenças?

Para propor um serviço que vise responder essa questão, realizou-se uma revisão bibliográfica acerca dos conceitos de bem-estar baseado no acesso, sustentabilidade e a criação de novos contextos de vida (MANZINI, 2017), criação de serviços colaborativos e relacionais (MANZINI, 2008; CIPOLLA E MANZINI, 2009) e definição do termo "comunidade" (BUBER, 1987). Utilizou-se o método HCD - Human Centred Design (IDEO, 2011), dividido em fases, para o desenvolvimento do projeto de serviço, o que gerou a proposta conceitual do serviço RAD (Relaxamento, Atividade Física e Descontração).

O intuito do RAD é inserir a prática de atividades físicas dentro de ambientes e grupos préformados, estimulando os usuários a co-criarem rotinas dentro de um campo confortável. Entendese que a proposta permite que o usuário conheça novas formas de se exercitar e relaxar dentro de rotinas diárias já estabelecidas, aumentando o grau de qualidades relacionais como confiança, comprometimento e empatia entre colegas de trabalho e vizinhos.

\section{Quadro Conceitual}

No contexto atual de mundo, percebe-se uma grande migração de pessoas seguindo em direção aos centros urbanos em busca de maior oferta de emprego, qualificação profissional, assistência hospitalar e entretenimento. Com a saturação populacional e a expansão vertical, "as cidades estão passando por uma crescente crise social" (CIPOLLA, 2012) que gera consequências como a falta de apoio social nas relações de vizinhança, uma grande sensação de solidão e o sedentarismo decorrente do conforto e velocidade que marcam a vida moderna.

Moradores de grandes metrópoles tendem a se distanciar um dos outros, vivendo em cômodos apartamentos sem se quer conhecer os vizinhos. Entretanto, Manzini (2017) acredita que existe uma força no encontro colaborativo, quando as pessoas estabelecem relações mais profundas e produzem vínculos sociais. Sendo assim, o objetivo deste trabalho é desenvolver um serviço voltado a prática de atividades físicas que vise o senso de comunidade e estimule o encontro relacional entre os usuários.

A prática de exercícios físicos em grupo integra as pessoas formando uma rede de apoio mútuo, na qual cada integrante funciona como um agente motivador. O termo comunidade é 
definido por Buber (1987) como a "união dos homens que se efetiva somente quando homens se aproximam uns dos outros e se encontram de modo imediato, na imediaticidade de seu dar e de seu receber". O autor acredita que existe uma comunidade quando os cidadãos "se encontram como únicos e responsáveis por tudo" e que somente desta maneira "pode haver abertura, participação, ajuda".

Nos serviços colaborativos o senso de comunidade é fortemente empregado. Os usuários atuam no processo de construção de valor a partir de relações simétricas, de forma que todos possuem o mesmo poder de transformação no serviço (MANZINI, 2008). Quando se trata de serviços colaborativos e relacionais, é necessário que os usuários co-criadores estejam dispostos a interagir com os demais para desenvolver qualidade nas relações (CIPOLLA, 2012). A construção dessas qualidades é entendida como um fator principal para o funcionamento dos processos, a qual sua ausência inviabiliza o serviço.

A construção das qualidades relacionais está relacionada a quanto às pessoas estão abertas e dispostas a interagir com as outras (CIPOLLA E MANZINI, 2009), quando o outro é entendido como uma presença viva, ainda que uma das partes represente uma empresa. A diferença para os serviços tradicionais é seu caráter de interação cíclica, em que cada ação feita por um beneficia de forma recíproca todos os participantes da rede (CIPOLLA E MANZINI, 2009).

\section{Metodologia}

Para a criação de um serviço colaborativo e relacional que incentive a prática de atividades físicas, foram utilizados métodos centrados no ser humano, como o HCD - Human Centred Design (IDEO, 2011) e ferramentas do design thinking de serviços, abordagem que foca nos seres humanos, e não nas organizações, buscando encontrar formas de mediar a relação entre organizações e stakeholders a fim de co-criarem valor (STICKDORN E SCHNEIDER, 2014).

O método HCD - Human Centred Design foi criado pela empresa de Design Thinking IDEO (2011) e é formado por três fases: Hear (ouvir), Create (criar) e Deliver (implementar). Na fase Hear (ouvir) foi possível identificar o desafio de design "Como criar um serviço que reúna pessoas em grupos durante a semana para práticas de atividades físicas em prol de prevenir doenças?". Dados foram coletados a partir de entrevistas semi-estruturadas com profissionais de educação física e usuários de diferentes idades e gêneros de serviços do setor na cidade do Rio de Janeiro. $O$ intuito era validar as hipóteses quanto a dificuldade de se manter o hábito de se exercitar. As perguntas utilizadas para nortear a coleta de dados foram:

- Qual é a sua relação com a prática de atividades físicas?

- O que considera um impedimento para ir à academia ou se exercitar ao ar livre?

- Você acredita que a falta de companhia é um fator que contribui para que as pessoas protelem os momentos de atividade física? Por quê?

- O que considera importante para gerar motivação na prática de atividades físicas?

- Qual fator considera pertinente para que uma pessoa sedentária construa o hábito?

Este questionário permitiu identificar como as pessoas enxergam a prática da atividade física em suas vidas, como conciliam junto às rotinas e o que consideram motivador para manter o hábito. Identificou-se que a falta de local adequado, falta de tempo e falta de companhia são fatores que dificultam a construção e permanência do hábito. 
Na fase Create (criar) foi desenvolvida a solução baseada nas dificuldades identificadas visando à construção de um serviço colaborativo ou relacional, o que levou ao conceito do serviço RAD. Como construto para o projeto, além dos dados coletados nas entrevistas, realizou-se um levantamento de serviços existentes que promovem a prática de atividade física tanto "indoor" como "outdoor". Posteriormente, serviços que promovem práticas de ginástica laboral em ambientes de trabalho foram analisados. Utilizou-se o critério da inovação como principal eixo na construção da solução.

Na fase Deliver (implementar), foram empregadas ferramentas do design de serviços (STICKDORN e SCHNEIDER, 2014) para desenvolver o modelo de negócio, o mapeamento dos processos, a estruturação da rede de parceiros (stakeholders) e o planejamento da execução do projeto como um sistema produto-serviço. As ferramentas utilizadas foram:

1. Personas: Representação de possíveis usuários através da criação de perfis fictícios.

2. Storyboard: Ferramenta de narração de imagens em sequência que permite visualização eficaz na demonstração da execução das atividades passo a passo.

3. Blueprint: Representação das interações do serviço, principais pontos de contato com o usuário e processos de retaguarda através de esquemas visuais.

4. Rede de Parceiros: Permite planejamento e visualização das interações de todos os stakeholders atuantes do serviço durante sua execução.

5. Logotipo: Permite identificar o serviço por meio de um símbolo gráfico.

6. Business Model Canvas: Demonstra a criação de valor envolvendo todos os stakeholders.

As ferramentas auxiliaram o processo de desenvolvimento do projeto conceitual, permitindo maior percepção a respeito dos requisitos fundamentais para solucionar os fatores que impedem o hábito de praticar atividades físicas.

\section{Resultados}

A partir da análise dos dados coletados, os seguintes pontos foram identificados como pertinentes para a criação de um novo serviço voltado para a área:

- Fazer atividades em grupo auxilia na construção do hábito devido as qualidades relacionais desenvolvidas, como confiança, comprometimento e empatia.

- Utilizar incentivos como forma de prolongar o hábito é entendido como uma boa prática.

- A rotina de atividades físicas pode ser entendida como um momento para relaxar e se divertir. Pode ser associada a práticas espirituais, exercícios de concentração e meditação.

- Entende-se como atividade física: exercícios em academias, práticas esportivas individuais ou coletivas, artes marciais, danças e práticas como yoga e tai chi chuan.

- A prática ao ar livre pode ser limitada por aspectos como falta de local apropriado, falta de tempo, falta de segurança e questões climáticas.

\subsection{Solução}

Para solucionar o problema do sedentarismo e promover a prática de atividades físicas considerando os pontos levantados na fase inicial de pesquisa, desenvolveu-se um serviço com base em três fatores que comprometem a construção do hábito: tempo, local e companhia. 
Intitulado pela sigla RAD (Relaxamento, Atividade Física e Descontração), o conceito do serviço é baseado na inserção da prática de atividade física de forma prazerosa dentro de ambientes que já fazem parte da rotina das pessoas, de modo que elas possam criar dinâmicas diferentes a cada semana e conhecer novas formas de se exercitar e relaxar.

O objetivo é prover um programa de atividades físicas e de relaxamento a ser introduzido a organizações de pessoas já existentes, como grupos de trabalho em ambientes corporativos, grupos de terceira idade, associações de bairros e turmas acadêmicas. Os integrantes co-criam as dinâmicas escolhendo e organizando a sequência de microatividades sugeridas através de plataformas online e offline para montar a rotina da semana.

Cada semana uma pessoa do grupo será escolhida como líder para auxiliar na condução das dinâmicas. Em fase inicial de aprendizado, um instrutor capacitado fará a apresentação do serviço e auxiliará na construção do hábito. Após o entendimento do sistema, o grupo terá total autonomia para criar as rotinas colaborativamente e executar as atividades físicas em grupo, tendo suporte do instrutor de forma presencial ou a distância caso necessário.

\subsection{Inovação}

Casos de serviços que visam incentivar ou inserir a prática de atividades físicas na rotina das pessoas foram analisados para auxiliar na construção do serviço com o intuito de identificar lacunas que possibilitam inovação. A tabela a seguir apresenta o conceito e a análise desses casos.

Quadro 1 - Análise de serviços de incentivo a prática de atividades físicas

\begin{tabular}{ll}
\hline Caso & Conceito \\
\hline Connect & $\begin{array}{l}\text { Serviço disponível a partir de um site no qual o } \\
\text { moves }\end{array}$ \\
& $\begin{array}{l}\text { usuário seleciona as atividades físicas } \\
\text { preferidas e encontra pessoas próximas com os }\end{array}$ \\
& mesmos interesses para que juntos possam \\
& praticar as atividades. Também é possível \\
& verificar locais apropriados disponíveis e buscar \\
& personal trainers próximos.
\end{tabular}

Heartbit Serviço disponível a partir de aplicativo para celular que converte o histórico de corridas, caminhadas ou pedaladas em pontos de um programa de fidelidade, que podem ser trocados por recompensas.

Verão Rio O Globo
Oferece, estimula e motiva as pessoas a praticarem atividade física ao ar livre durante o verão. A iniciativa é realizada pelo jornal OGLOBO no posto 10 da praia de Ipanema e ainda oferece programas culturais e empréstimos de barracas e cadeiras para os assinantes.

\section{Análise}

Auxilia o usuário apresentando opções para solucionar as dificuldades de falta de local, tempo e companhia, porém não garante eficácia. Entende-se como um serviço colaborativo, uma vez que os usuários colaboram inserindo informações no site, e relacional, no momento de encontro dos usuários para a prática.

Beneficia os usuários que são ativos fisicamente, usuários iniciantes tendem a desistir, pois para obter benefício real é necessária uma rotina intensa a qual não possuem o hábito em um primeiro momento. Não apresenta soluções para as dificuldades de local, tempo e companhia.

Determina um local que ficará à disposição para as práticas, que são guiadas por profissionais. Apresenta solução para a falta de companhia, pois as práticas ocorrem coletivamente, mas como são desempenhadas de forma individual, não o configura como serviço relacional. Não soluciona a falta de tempo.

Fonte: Elaborado pelas autoras conforme dados de Connect Moves (2017), Heartbit (2017) e Verão Rio O Globo (2017). 
A partir dos casos analisados foi possível verificar que o fator falta de tempo é o mais difícil de ser solucionado. Ainda que motivadas, as pessoas não conseguem equacionar seus compromissos para manter uma rotina saudável, e é muitas vezes a falta de local apropriado e seguro que dificulta a prática no horário disponível, o que leva a maior necessidade de companhia.

Sendo assim, o RAD foi elaborado de forma que as atividades sejam inseridas dentro de grupos de pessoas já conhecidas e com certo grau de intimidade, em horários e locais que já fazem parte da rotina, sendo uma solução para a dificuldade de local, tempo e companhia. Serviços semelhantes que promovem práticas de ginástica laboral em ambientes de trabalho foram analisados para o desenvolvimento de vantagens competitivas.

Quadro 2 - Análise de serviços de ginástica laboral e saúde ocupacional

\begin{tabular}{|c|c|}
\hline Caso & Conceito \\
\hline Sunyata & $\begin{array}{l}\text { Serviço de consultoria para o ambiente } \\
\text { corporativo. Desenvolve e gerencia programas } \\
\text { para combater o estresse e o sedentarismo, } \\
\text { como serviços de massagem, ginástica laboral } \\
\text { e reflexologia podal. }\end{array}$ \\
\hline
\end{tabular}

Vida em Forma

Life PQV

Presta serviços voltados a atividade física para empresas e grupos em geral visando melhorar a qualidade de vida dos usuários. Dentre seus programas, oferece serviços de ginástica laboral, laudo ergonômico, massagens, eventos de lazer, grupos de corrida e caminhada e atividades em condomínios.

\section{Análise}

Soluciona a falta de local, tempo e companhia. Possui caráter fisioterapêutico. Os usuários são submetidos a massagens através de profissionais ou executam ginástica laboral individual. Não se enquadra como serviço colaborativo e relacional.

Promove soluções para as dificuldades de local, tempo e companhia. Oferece serviços de cunho terapêutico e profilático. A ginástica laboral é realizada individualmente. Oferece serviços relacionados a relaxamento, porém o usuário não participa na co-criação, sendo agente passivo e apenas receptor do programa.

Promove soluções para as dificuldades de local, tempo e companhia. O serviço de ginástica laboral é realizado individualmente. As atividades em condomínios e eventos de lazer são realizadas a partir da prática de esportes, atividades culturais e recreativas em grupo, com gradações de caráter colaborativo e relacional no decorrer da execução.

Fonte: Elaborado pelas autoras conforme dados de Sunyata (2017), Vida em Forma (2017) e Life PQV (2017).

Os serviços que inserem atividades físicas e de relaxamento em ambientes e grupos já formados em sua maioria possuem caráter terapêutico, mas sem o cuidado de tornar o momento divertido. Os serviços que promovem alternativas mais diversificadas com caráter esportivo possuem programas fechados direcionados para perfis diferentes de público-alvo. No geral, os usuários não têm poder de escolha sobre as atividades a serem executadas nem quanto a sua periodicidade. Logo, pode-se observar que a proposta do RAD possui benefícios além das propostas convencionais, conforme o quadro 3 abaixo. 
Quadro 3 - Comparação entre serviços semelhantes e o modelo proposto

\section{Serviços semelhantes}

Serviço de ginástica laboral (alongamentos e exercícios) e massagens em ambientes corporativos.

Soluciona as dificuldades de local, tempo e companhia. Serviços de caráter terapêutico e ocupacional.

O usuário executa as ginásticas propostas e recebe passivamente massagens.

O público-alvo é formado por empresas e ambientes corporativos.

\section{RAD}

Serviço que habilita grupos co-criarem sequências de atividades físicas para montar a rotina da semana.

Soluciona as dificuldades de local, tempo e companhia.

Serviço de caráter esportivo e de lazer.

O usuário co-cria a rotina de exercícios, determina o tempo, a periodicidade e a executa em grupo.

O público-alvo é formado por grupos pré-formados com encontros presenciais de qualquer natureza.

Fonte: Elaborado pelas autoras

A proposta do RAD é inovadora por proporcionar poder de escolha aos usuários, facilitando a organização de rotinas de atividades físicas através de plataformas habilitantes online (aplicativo) offline (jogo de tabuleiro), que informam as instruções necessárias para a execução das microatividades. Pode ser aderido por grupos de qualquer natureza e apresenta diversas atividades de cunho esportivo e de lazer para que os usuários possam experimentar novas possibilidades e adaptar a rotina conforme suas necessidades da semana.

\subsection{Usuários envolvidos}

Levando em consideração que o serviço é direcionado a grupos pré-formados, foram desenvolvidas personas que representam os usuários finais e líderes que podem aderir o serviço.

\section{Figura 1 - Personas}

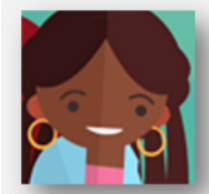

Joana Oliveira, $\mathbf{3 5}$ anos (Profissional de RH)

Joana trabalha na equipe de $\mathrm{RH}$ de uma grande empresa e acredita que o programa de serviços RAD possa trazer mais bem-estar e desenvolver criatividade nas suas tarefas diárias. Como os processos de RH dentro de grandes empresas tendem a ser muito tradicionais, acredita que melhorar a relação da equipe proporcionará diferentes perspectivas de descontração no dia a dia na empresa.

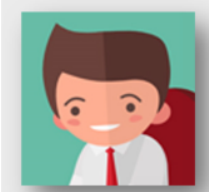

José Carlos, 67 anos (Presidente da Associação dos Moradores)

José Carlos é um motivador nato e sempre busca engajar e envolver as pessoas nas reuniões quinzenais. Ele acredita que o RAD poderá aproximar mais a vizinhança e este tipo de ação é um grande sonho para o presidente que gosta de ver as pessoas unidas e se divertindo.

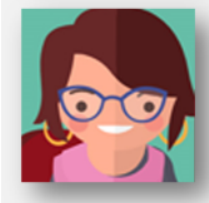

Flavia Brandão, $\mathbf{3 0}$ anos (Arquiteta de um estúdio)

Flavia trabalha em uma pequeno estúdio de arquitetura e acredita que os serviços do RAD poderão entrosar a equipe e fomentar novas atividades sociais. Como trabalham por projetos, muitas vezes excedem os horários para finalizar uma obra. O RAD pode proporcionar bem-estar e melhorar a empatia da equipe.

Fonte: Adaptado de Powtoon (2017). 


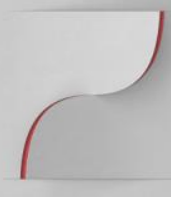

Pesquisa \&

Desenvolvimento

em Design

\section{Artigo Completo}

\subsection{Proposta conceitual}

O RAD é um serviço que auxilia a inserção de atividades físicas na vida diária das pessoas. Através de plataformas habilitantes os usuários obtêm informações sobre as microatividades e colaborativamente montam uma série de exercícios a serem praticados durante a semana. $O$ serviço provê dois tipos de plataforma habilitante: aplicativo online e jogo de tabuleiro. A escolha do modelo a ser utilizado será feita pelo grupo.

Em um primeiro momento, uma equipe apresenta o serviço ao grupo, instrui sobre o funcionamento e auxilia na primeira prática (protótipo do serviço). Após o período de aprendizado, o grupo executa o serviço de forma autônoma, solicitando suporte presencial ou remoto à equipe caso necessário. Os membros do grupo escolhem as microatividades a serem desempenhadas, a duração e a periodicidade da rotina. A proposta do serviço é disponibilizar principalmente exercícios de caráter esportivo ou de relaxamento em que os usuários possam executar em conjunto (duplas, trios ou equipes), assim desenvolvendo qualidades relacionais como confiança, intimidade e promovendo o senso de pertencimento ao grupo.

Portanto, entende-se que o RAD é um sistema produto-serviço que utiliza plataformas habilitantes como meio de suporte para que grupos e associações já existentes possam se autoorganizar para a prática de atividades físicas. O serviço provê acompanhamento aos grupos conforme necessário e disponibiliza novas microatividades periodicamente.

\subsection{Estética e estrutura das interações}

Para demonstrar a interação entre os membros nos momentos de co-criação e execução das rotinas, gerou-se um storyboard utilizando o contexto da persona "Flávia Brandão", que trabalha em um estúdio de arquitetura. $\mathrm{O}$ grupo já possui autonomia para tomar decisões e seguir com a prática da rotina nesta fase.

Figura 2 - Storyboard da co-criação do serviço

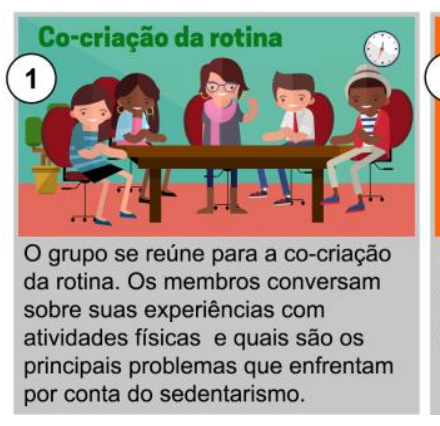

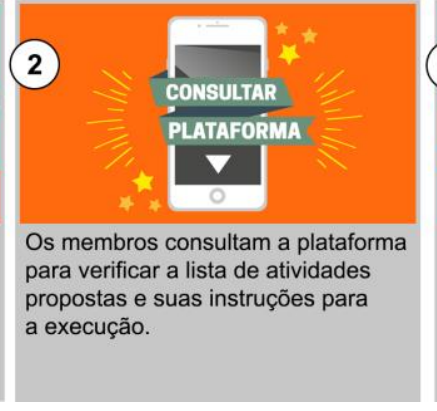

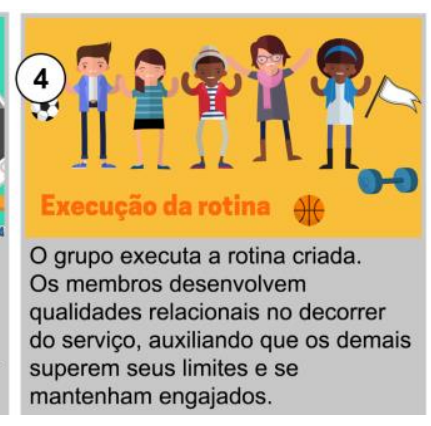

Fonte: Adaptado de Powtoon (2017).

O blueprint apresentado na figura 3 representa a visão geral da estrutura das interações do serviço, demonstrando os níveis de profundidade de cada processo e os pontos de contato serviçousuário. Já o blueprint da figura 4 demonstra a visão micro do momento de co-criação das rotinas e execução, entendido como o ponto alto do serviço por concretizar o objetivo principal de fazer com que as pessoas se exercitem. 
Figura 3-Blueprint do serviço RAD

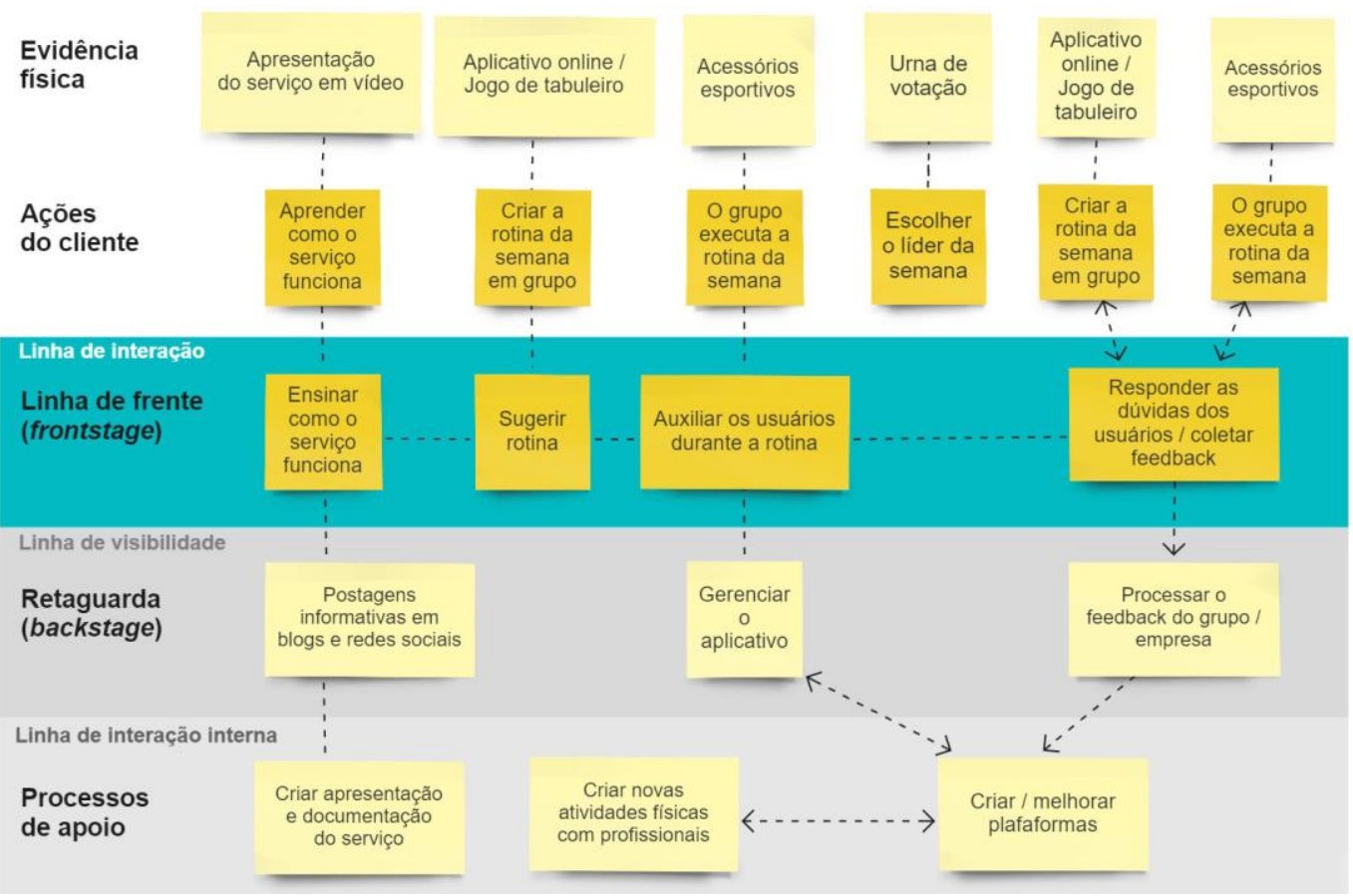

Fonte: Adaptado de Stickdorn e Schneider (2014).

Figura 4-Blueprint do momento de execução do serviço RAD pelo grupo

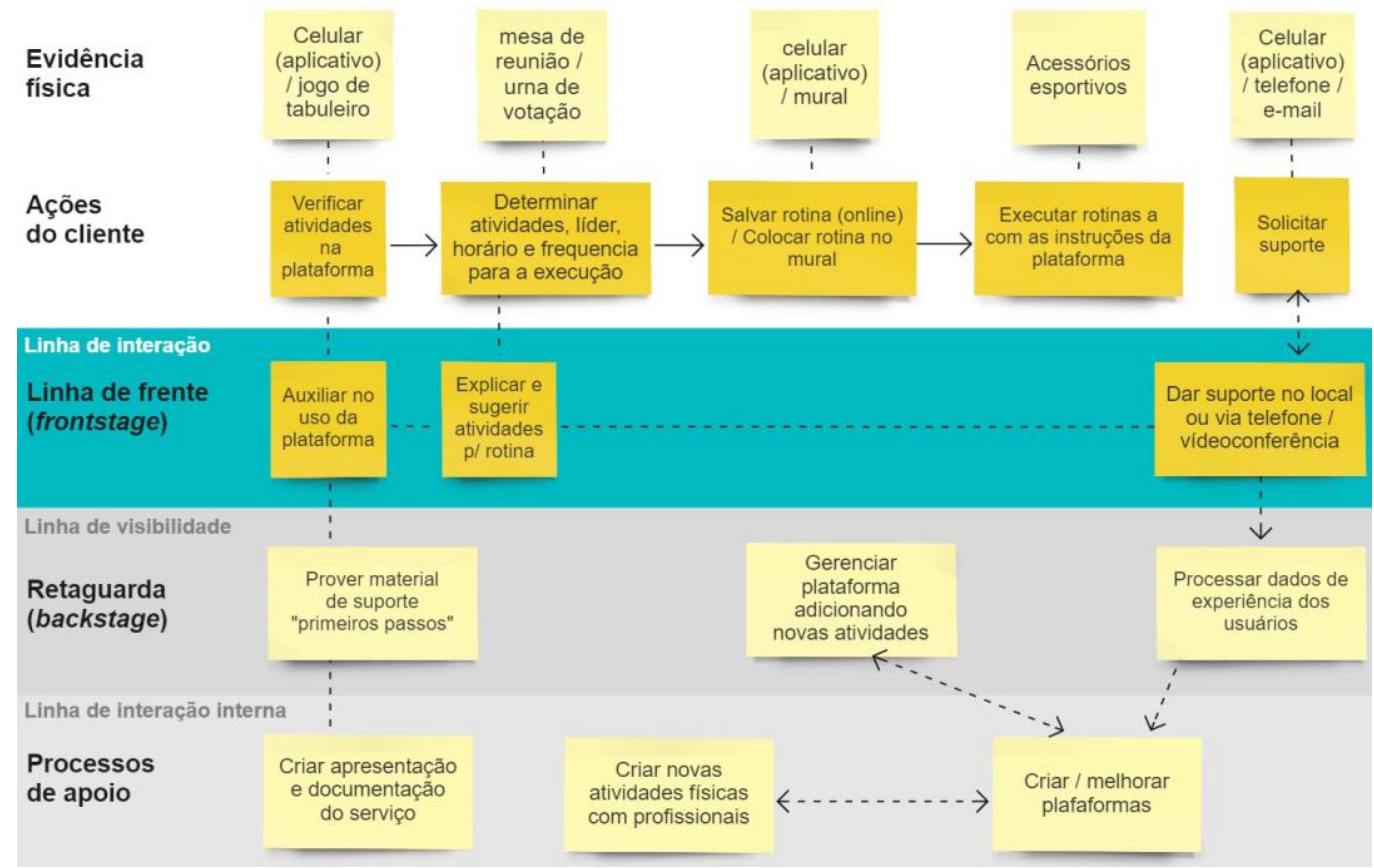

Fonte: Adaptado de Stickdorn e Schneider (2014). 


\subsection{Rede de parceiros}

Para melhor visualização da rede de parceiros (stakeholders) e suas relações entre si e com o serviço, elaborou-se o quadro 4 abaixo, considerando as áreas de interseção em cor laranja como os objetivos principais entre os mesmos grupos. Áreas em branco representam que os respectivos grupos não interagem no sistema.

Quadro 4-Rede de parceiros do serviço RAD

\begin{tabular}{|c|c|c|c|c|c|c|c|}
\hline & $\begin{array}{l}\text { Equipe de } \\
\text { Gerenciamento } \\
\text { do serviço }\end{array}$ & $\begin{array}{l}\text { Profissionais de } \\
\text { atividades } \\
\text { físicas }\end{array}$ & $\begin{array}{l}\text { Equipe de } \\
\text { apresentação e } \\
\text { assistência do } \\
\text { serviço }\end{array}$ & $\begin{array}{l}\text { Equipe de } \\
\text { criação e } \\
\text { desenvolvimento } \\
\text { (plataformas } \\
\text { habilitantes) }\end{array}$ & $\begin{array}{l}\text { Provedores } \\
\text { de acessórios } \\
\text { esportivos }\end{array}$ & $\begin{array}{l}\text { Equipe de } \\
\text { análise e } \\
\text { processamento } \\
\text { de dados } \\
\text { (feedbacks) }\end{array}$ & $\begin{array}{l}\text { Empresa, } \\
\text { grupo ou } \\
\text { associação } \\
\text { contratante }\end{array}$ \\
\hline $\begin{array}{l}\text { Equipe de } \\
\text { Gerenciamento } \\
\text { do serviço }\end{array}$ & $\begin{array}{l}\text { Identificar } \\
\text { novas } \\
\text { perspectivas } \\
\text { de aplicação } \\
\text { do serviço, } \\
\text { gerenciar } \\
\text { processos } \\
\text { internos e } \\
\text { externos. }\end{array}$ & $\begin{array}{l}\text { Passar } \\
\text { parâmetros que } \\
\text { garantem a } \\
\text { adequação das } \\
\text { atividades ao } \\
\text { serviço. }\end{array}$ & $\begin{array}{l}\text { Treinar equipe } \\
\text { sobre o } \\
\text { funcionamento } \\
\text { do serviço. }\end{array}$ & $\begin{array}{l}\text { Identificar e } \\
\text { transmitir } \\
\text { possiveis } \\
\text { melhorias. }\end{array}$ & $\begin{array}{l}\text { Aquisição de } \\
\text { equipamentos, } \\
\text { parcerias p/ } \\
\text { geração de } \\
\text { incentivos aos } \\
\text { usuários. }\end{array}$ & $\begin{array}{l}\text { Informar novas } \\
\text { perspectivas } \\
\text { do serviço, } \\
\text { melhorias } \\
\text { e adaptações } \\
\text { gerenciais } \\
\text { necessárias. }\end{array}$ & $\begin{array}{l}\text { Gerenciar a } \\
\text { aplicação do } \\
\text { serviço nas } \\
\text { empresas. }\end{array}$ \\
\hline $\begin{array}{l}\text { Profissionais de } \\
\text { atividades } \\
\text { fisicas }\end{array}$ & $\begin{array}{l}\text { Conhecimento } \\
\text { especifico sobre } \\
\text { as funções de } \\
\text { cada atividade } \\
\text { proposta }\end{array}$ & $\begin{array}{l}\text { Criar micro } \\
\text { atividades } \\
\text { reorganizáveis } \\
\text { para execução } \\
\text { em grupo. }\end{array}$ & $\begin{array}{l}\text { Instruir e treinar } \\
\text { a equipe a } \\
\text { respeito das } \\
\text { atividades } \\
\text { criadas. }\end{array}$ & $\begin{array}{l}\text { Passar } \\
\text { informações } \\
\text { sobre as micro } \\
\text { atividades e co- } \\
\text { criar material de } \\
\text { instrução } \mathrm{p} / \text { as } \\
\text { plataformas. }\end{array}$ & $\begin{array}{l}\text { Lista de } \\
\text { equipamentos } \\
\text { básicos } \\
\text { necessários. }\end{array}$ & $\begin{array}{l}\text { Instrução } \\
\text { técnica das } \\
\text { atividades para } \\
\text { análise dos } \\
\text { dados }\end{array}$ & $\begin{array}{l}\text { Introdução de } \\
\text { novas micro } \\
\text { atividades ao } \\
\text { longo do tempo. }\end{array}$ \\
\hline $\begin{array}{l}\text { Equipe de } \\
\text { apresentação } \\
\text { e assistência } \\
\text { do serviço }\end{array}$ & $\begin{array}{l}\text { Levantar } \\
\text { questões } \\
\text { práticas do } \\
\text { serviço a serem } \\
\text { repensadas. }\end{array}$ & $\begin{array}{l}\text { Auxiliar na } \\
\text { criação de novas } \\
\text { atividades com } \\
\text { base em } \\
\text { questões locais. }\end{array}$ & $\begin{array}{l}\text { Apresentar o } \\
\text { funcionamento } \\
\text { do serviço } \\
\text { para o grupo, } \\
\text { ensinar } \\
\text { o sistema e } \\
\text { dar assistência } \\
\text { presencial ou } \\
\text { remota. }\end{array}$ & $\begin{array}{l}\text { Auxiliar na } \\
\text { verificação de } \\
\text { mudanças } \\
\text { incrementais / } \\
\text { prototipação do } \\
\text { serviço. }\end{array}$ & $\begin{array}{l}\text { Apresentação } \\
\text { do serviço para } \\
\text { concretização } \\
\text { de parcerias. }\end{array}$ & $\begin{array}{l}\text { Informar } \\
\text { feedbacks dos } \\
\text { membros dos } \\
\text { grupos e os } \\
\text { resultados } \\
\text { obtidos pela } \\
\text { prática ao longo } \\
\text { do tempo. }\end{array}$ & $\begin{array}{l}\text { Instrução sobre } \\
\text { o funcionamento } \\
\text { do serviço, } \\
\text { assistência } \\
\text { presencial } \\
\text { ou remota } \\
\text { conforme } \\
\text { necessidade. }\end{array}$ \\
\hline $\begin{array}{l}\text { Equipe de } \\
\text { criação } \\
\text { /desenvolviment } \\
\text { o (plataformas } \\
\text { habilitantes) }\end{array}$ & $\begin{array}{l}\text { Instrução de } \\
\text { uso, } \\
\text { gerenciamento } \\
\text { e controle das } \\
\text { plataformas. }\end{array}$ & $\begin{array}{l}\text { Elaborar } \\
\text { intercambialidade } \\
\text { das micro } \\
\text { atividades e } \\
\text { parâmetros } \\
\text { básicos da rotina. }\end{array}$ & $\begin{array}{l}\text { Instrução de } \\
\text { uso, } \\
\text { gerenciamento } \\
\text { e controle das } \\
\text { plataformas. }\end{array}$ & $\begin{array}{l}\text { Criar plataforma } \\
\text { habilitante do } \\
\text { serviço online } \\
\text { que permita } \\
\text { autonomia e } \\
\text { criação de } \\
\text { rotinas pelo } \\
\text { usuário. }\end{array}$ & $\begin{array}{l}\text { Inserção de } \\
\text { propagandas/ } \\
\text { indicações dos } \\
\text { parceiros nas } \\
\text { plataformas. }\end{array}$ & $\begin{array}{l}\text { Informações } \\
\text { técnicas sobre o } \\
\text { funcionamento } \\
\text { das plataformas } \\
\text { habilitantes para } \\
\text { analise dos } \\
\text { dados. }\end{array}$ & $\begin{array}{l}\text { Promover } \\
\text { melhorias } \\
\text { na interação } \\
\text { entre os } \\
\text { usuários e as } \\
\text { plataformas } \\
\text { habilitantes. }\end{array}$ \\
\hline $\begin{array}{l}\text { Provedores } \\
\text { de acessórios } \\
\text { esportivos }\end{array}$ & $\begin{array}{l}\text { Informação } \\
\text { sobre } \\
\text { disponibilidade } \\
\text { de } \\
\text { equipamentos, } \\
\text { custos. }\end{array}$ & $\begin{array}{l}\text { Disponibilizar } \\
\text { acessórios } \\
\text { esportivos } \mathrm{p} / \mathrm{a} \\
\text { criação das } \\
\text { práticas. }\end{array}$ & $\begin{array}{l}\text { Informação } \\
\text { sobre } \\
\text { equipamentos e } \\
\text { programa de } \\
\text { descontos. }\end{array}$ & $\begin{array}{l}\text { Instrução técnica } \\
\text { sobre possiveis } \\
\text { acessórios a } \\
\text { serem utilizados } \\
\text { nas práticas. }\end{array}$ & $\begin{array}{l}\text { Fornecer } \\
\text { equipamento } \\
\text { s e programa } \\
\text { de descontos } \\
\text { para os } \\
\text { contratantes } \\
\text { do serviço. }\end{array}$ & & $\begin{array}{l}\text { Fornecer } \\
\text { programa de } \\
\text { descontos aos } \\
\text { usuários. }\end{array}$ \\
\hline $\begin{array}{l}\text { Equipe de } \\
\text { análise e } \\
\text { processamento } \\
\text { de dados } \\
\text { (feedbacks) }\end{array}$ & $\begin{array}{l}\text { Informação de } \\
\text { dados sobre } \\
\text { experiência do } \\
\text { usuário }\end{array}$ & $\begin{array}{l}\text { Informar dados } \\
\text { pertinentes } \\
\text { analisados sobre } \\
\text { a experiência do } \\
\text { usuário }\end{array}$ & $\begin{array}{l}\text { Informações } \\
\text { qualitativas } \\
\text { sobre diferentes } \\
\text { abordagens de } \\
\text { introdução do } \\
\text { sistema ao } \\
\text { grupo. }\end{array}$ & $\begin{array}{l}\text { Informar dados } \\
\text { pertinentes } \\
\text { analisados sobre } \\
\text { a experiência do } \\
\text { usuário. }\end{array}$ & $\begin{array}{l}\text { Informação } \\
\text { sobre usos de } \\
\text { equipamentos } \\
\text { pelos usuários. }\end{array}$ & $\begin{array}{l}\text { Levantar dados } \\
\text { quantitativos } \\
\text { e qualitativos } \\
\text { para } \\
\text { identificação } \\
\text { de melhorias } \\
\text { e novas } \\
\text { perspectivas } \\
\text { do serviço. }\end{array}$ & $\begin{array}{l}\text { Respostas aos } \\
\text { feedbacks dos } \\
\text { contratantes } \\
\text { ou usuários. }\end{array}$ \\
\hline $\begin{array}{l}\text { Empresa/ Grupo } \\
\text { I associação } \\
\text { contratante }\end{array}$ & $\begin{array}{l}\text { Recurso } \\
\text { financeiro }\end{array}$ & & $\begin{array}{l}\text { Informar } \\
\text { motivação na } \\
\text { aderência ao } \\
\text { serviço, perfil } \\
\text { dos membros, } \\
\text { espaços físicos } \\
\text { disponiveis. }\end{array}$ & & & & $\begin{array}{l}\text { Co-criar } \\
\text { rotinas de } \\
\text { atividades } \\
\text { semanais em } \\
\text { grupo. Efetuar } \\
\text { a prática das } \\
\text { rotinas. }\end{array}$ \\
\hline
\end{tabular}

Fonte: Elaborado pelas autoras 


\subsection{Identidade Visual}

O logotipo é formado por um símbolo e uma representação gráfica do nome do serviço com tipografia estilo stencil, com o intuito de demonstrar descontração, e seu traço é robusto, para demonstrar força e objetividade.

A cartela de cores estudada para a representação da marca é composta por tons de azul turquesa, laranja e verde esmeralda. $\mathrm{O}$ azul transmite segurança e produtividade, associado com água denota ritmo e rápida adaptação. A cor laranja representa confiança, alegria e diversão. $\mathrm{O}$ verde é associado com saúde, tranquilidade e relaxamento.

O símbolo é formado pela repetição de um elemento circularmente, demonstrando o espírito de equipe que o serviço promove. O elemento consiste em um círculo e um traço côncavo e representa um indivíduo de braços para o alto, o que faz alusão aos momentos de comemoração em eventos esportivos e momentos de superação.

\section{Figura 5 - Logotipo do serviço RAD e aplicações}
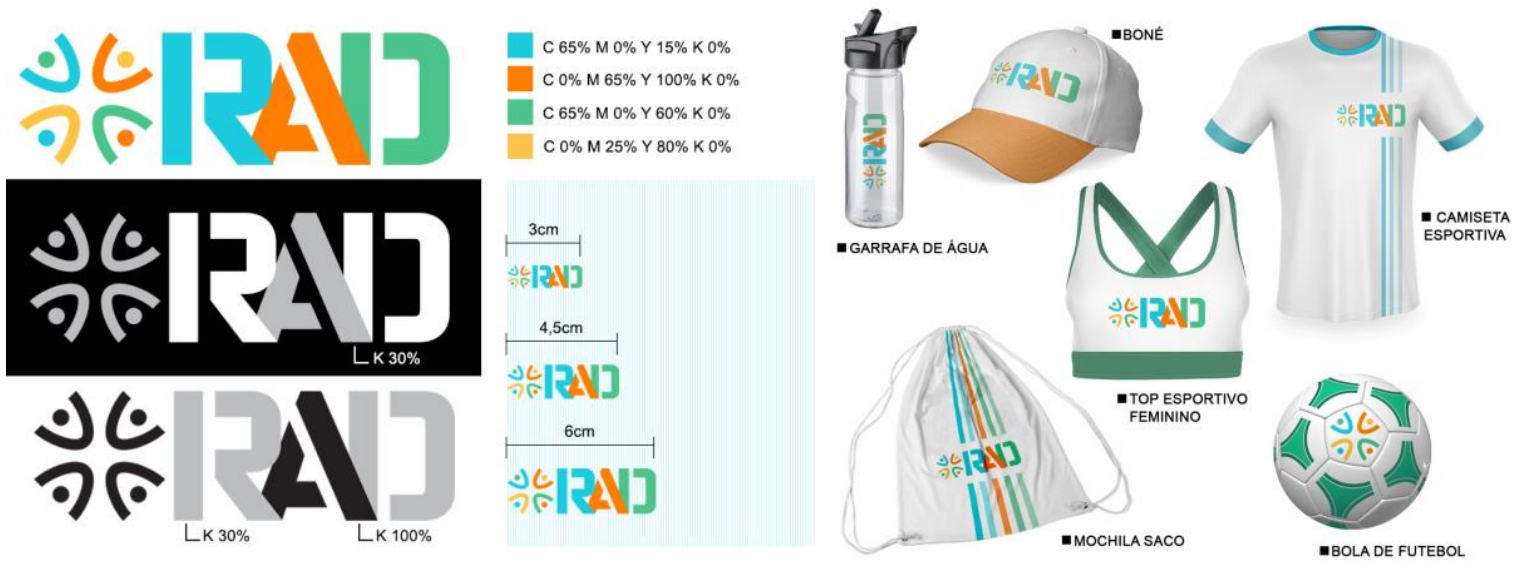

Fonte: Elaborado pelas autoras

\subsection{Modelo de Negócio}

O modelo de negócio do serviço RAD envolve a criação de valor para três esferas de stakeholders. Para os usuários finais, ou seja, os membros dos grupos, o serviço inclui atividades físicas dentro do horário de trabalho ou reunião pré-existente, auxilia na redução de estresse, melhora a qualidade de vida e as relações interpessoais no ambiente. No âmbito organizacional, as empresas obtêm melhores resultados através do aumento de engajamento dos membros em atividades em conjunto. Para os parceiros, o serviço torna-se uma oportunidade de aproximação aos clientes em potencial, permitindo que um trabalho de fidelização seja feito.

Redução de horas de trabalho, ingressos para eventos de lazer e cupons de desconto podem ser utilizados como incentivos para que os usuários se mantenham engajados a prática das atividades, assim como disponibilizar constantes atualizações das plataformas com conteúdo de novas atividades. 
Figura 6-Business Model Canvas do serviço RAD

\begin{tabular}{|c|c|c|c|c|c|c|}
\hline \multirow{2}{*}{$\begin{array}{l}\text { Parcerias chave } \\
\text { - Personal trainers; } \\
\text { - Professores de } \\
\text { educação física; } \\
\text { - Instrutores de Yoga, } \\
\text { Tai chi chuan; } \\
\text { - Empresas e grandes } \\
\text { associações; } \\
\text { - Provedores de } \\
\text { serviços online; }\end{array}$} & \multicolumn{2}{|c|}{$\begin{array}{l}\text { Atividades chave } \\
\text { - Dispor micro } \\
\text { atividades físicas a } \\
\text { serem organizadas } \\
\text { em grupo para } \\
\text { formação de rotina e } \\
\text { execução durante a } \\
\text { semana. }\end{array}$} & \multirow{2}{*}{$\begin{array}{l}\text { Proposta de valor } \\
\text { - Motivação para } \\
\text { a prática de atividades } \\
\text { físicas; } \\
\text { - Levar a atividade } \\
\text { física para a rotina } \\
\text { diária atual dos } \\
\text { usuários; } \\
\text { - Promover momentos } \\
\text { de diversão e } \\
\text { descontração durante } \\
\text { a semana; }\end{array}$} & \multicolumn{2}{|c|}{$\begin{array}{l}\text { Relações com clientes } \\
\text { - Assistência } \\
\text { personalizada; } \\
\text { - Acompanhamento } \\
\text { dos resultados a } \\
\text { Partir de exames; }\end{array}$} & \multirow[t]{2}{*}{$\begin{array}{l}\text { Segmentos de } \\
\text { mercado } \\
\text { - Empresas; } \\
\text { - Condomínios } \\
\text { residenciais; } \\
\text { - Associações de bairro; } \\
\text { - Grupos de terceira } \\
\text { idade; } \\
\text { - Grupos de estudo/ } \\
\text { leitura; }\end{array}$} \\
\hline & \multicolumn{2}{|c|}{$\begin{array}{l}\text { Recursos chave } \\
\text { - Recursos humanos; } \\
\text { - Lugares físicos } \\
\text { pré-estabelecidos; }\end{array}$} & & \multicolumn{2}{|c|}{$\begin{array}{l}\text { Canais } \\
\text {-Canais físicos: } \\
\text { ambientes de trabalho, } \\
\text { prédios, clubes etc; } \\
\text {-Canais virtuais: } \\
\text { aplicativo, website, } \\
\text { redes sociais; }\end{array}$} & \\
\hline \multicolumn{2}{|c|}{$\begin{array}{l}\text { Estrutura de custos } \\
\text { - Desenvolvimento das plataformas; } \\
\text { - Contratação de profissionais; } \\
\text {-Aquisição de acessórios esportivos; }\end{array}$} & \multicolumn{3}{|c|}{$\begin{array}{l}\text { Trocas não-monetárias } \\
\text { e colaborativas } \\
\text { - Coleção de rotinas preferidas } \\
\text { do grupo (histórico); } \\
\text { - Dados quantitativos e qualitativos } \\
\text { para pesquisas científicas; }\end{array}$} & \multicolumn{2}{|c|}{$\begin{array}{l}\text { Fontes de renda } \\
\text { - Venda do jogo de tabuleiro; } \\
\text { - Assinatura semestral do aplicativo; } \\
\text { - Parcerias com empresas contratantes; } \\
\text { - Recebimentos via cartão de crédito, } \\
\text { boleto bancário e débito em conta. }\end{array}$} \\
\hline
\end{tabular}

Fonte: Adaptado de Cipolla, Serpa e Afonso (2017).

Os custos envolvidos no negócio envolvem a contratação de profissionais qualificados para as funções de linha de frente, retaguarda e processos, assim como a criação e o gerenciamento das plataformas, contratação de serviços terceirizados e aquisição de acessórios esportivos.

A contratação de profissionais pode ser realizada através de contrato CLT ou através de parcerias com profissionais autônomos. Os custos relacionados a criação e gerenciamento das plataformas estão relacionados com a aquisição de aparato tecnológico (software e hardware) necessário, contratação de provedores de serviços online e serviços gráficos especializados.

A aquisição de acessórios esportivos pode ser realizada através de compra ou custeada por empresas parceiras do setor esportivo.

A fonte de renda principal do serviço é a venda de planos de assinatura semestral do aplicativo. O plano básico dá acesso apenas a plataforma e a um número restrito de assistência personalizada no local, o plano mais completo dá acesso a acompanhamento médico e acessórios esportivos. A venda do jogo de tabuleiro com acessórios esportivos é feita separadamente, sendo contratada a assistência personalizada separadamente quando necessário.

Acredita-se que este modelo de negócio permite o desdobramento de mais canais de distribuição e mais fontes de renda conforme a consolidação de parcerias com profissionais, empresas do ramo esportivo e até mesmo com as empresas contratantes que podem se tornar parceiras na construção de valor do serviço.

\section{Considerações finais}

Sendo o RAD um serviço que visa a inserção de atividades físicas na vida diária das pessoas, o propósito é justamente promover o início de novos hábitos, permitindo que o grupo tenha total autonomia quanto às decisões relacionadas a atividades, frequência e execução. Se o grupo não se engajar ao sistema, não há serviço. O grupo toma decisões quanto à formação das rotinas, 
as executa e produz o resultado. A criação de valor do serviço está no que é produzido pelos usuários colaborativamente e não no que a empresa provê aos usuários, como nos modelos tradicionais de serviço. Os usuários não consomem o serviço, eles o executam. Dois grupos distintos em um mesmo ambiente de trabalho podem co-criar rotinas e ter resultados totalmente diferentes.

Conforme Manzini (2008) aponta, a transição para hábitos mais sustentáveis é um processo de aprendizagem social, e o serviço proposto trabalha nesta esfera, promovendo a aprendizagem e a construção do hábito. Os usuários poderão conhecer novas atividades, esportes, técnicas de relaxamento e assim desenvolverem novos hábitos pessoais em suas vidas. Neste caso, os usuários não são beneficiados apenas enquanto estão co-criando o serviço, o benefício é estendido e passa a ser experiência de vida.

O RAD é direcionado para grupos pré-formados, ou seja, os membros já se conhecem e possuem um grau razoável de confiança. Acredita-se que ao longo do serviço o grupo fortaleça suas relações interpessoais, ampliando a confiança e o desenvolvimento de qualidades como a empatia e a intimidade. Porém, esse desenvolvimento não é garantido, pois é um aspecto que fica a encargo dos próprios usuários. Caso as qualidades relacionais não sejam fortalecidas, pode haver desmotivação, e assim o serviço tende a não ser efetuado.

Analisando a jornada do RAD a partir do modelo de matriz de serviços colaborativos e relacionais na figura 7 abaixo (CIPOLLA E MANZINI, 2009), constatou-se gradações destas características em diferentes fases, da apresentação do serviço à execução autônoma.

Figura 7 - Posicionamento das fases do serviço RAD na matriz de serviço colaborativos e relacionais

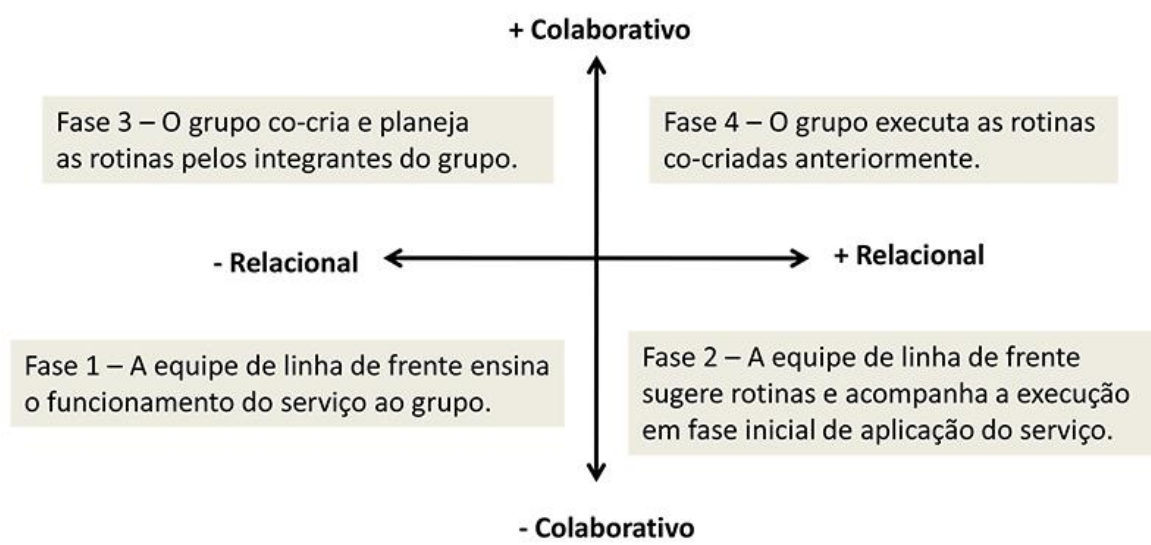

Fonte: Adaptado de Cipolla e Manzini (2009).

Nas fases 1 e 2 a equipe de linha de frente auxilia na aprendizagem dos usuários quanto as particularidades do serviço. Na fase 1 são transmitidos os conceitos do RAD, não apresentando características colaborativas ou relacionais. Na fase 2 os usuários já começam a construir qualidades relacionais, uma vez que já estão envolvidos com a prática das atividades, ainda que não estejam totalmente autônomos na execução do serviço.

Nas fases 3 e 4 o grupo já possui autonomia quanto a co-criação e execução das rotinas, portanto são fases em que o caráter colaborativo e relacional é proeminente. Ao longo do ciclo de vida do serviço entende-se que as fases 3 e 4 serão repetidas ciclicamente, sem dependência de agentes externos. 
Tendo em vista os aspectos observados, pode-se concluir que o RAD é um sistema produtoserviço de caráter colaborativo e relacional. Habilita os usuários a construírem o hábito de praticar atividades físicas suprindo dificuldades como a falta de local adequado, falta de tempo na vida diária e falta de companhia. A partir do serviço, os usuários desenvolvem melhor qualidade de vida, tomam conhecimento de novos esportes, exercícios e métodos saudáveis, criam novos hábitos e fortalecem qualidades relacionais que trazem benefícios individuais e coletivos para a comunidade.

\section{Referências}

BUBER, M. Sobre comunidade. São Paulo: Perspectiva, 1987.

CIPOLLA, C. Creative communities as "relational" inovations: a service design approach. In: JÉGOU, F.; MANZINI, E. (Ed.). Collaborative Services: Social innovationand design for sustainability. Milão: EdizioniPOLI.design, 2008. p.151-153.

CIPOLLA, C; MANZINI, E. Relational services. Knowledge Technology \& Policy, [S.I.], v. 22, p. 45-50, Springer, 2009.

CIPOLLA, C. Solutions for Relational Services. In: SatuMiettinen; AnuValtonen. (Org.). Service Design with Theory.Discussions on Change, Value and Methods. 1ed.Rovaniemi: LUP - Lapland University Press, 2012, v., p. 34-40.

CIPOLLA, C; SERPA, Bibiana Oliveira; AFONSO, Rita. Design for social innovation between university and the broader society: a mutual learning process. MIX Sustentável, v. 3, n. 4, p. 109-118, 2017.

CONNECT MOVES. Conectando pessoas para a prática de atividades físicas. In: Facebook, 2017. (http://www.facebook.com/connectmoves)

HEARTBIT. Faça exercícios físicos e ganhe pontos patrocinados que te ajudam a adquirir voos e muito mais. In: Heartbit, 2017. (http://heartbit.me)

LIFE PQV. Promoção em qualidade de vida. In: Life PQV, 2017. (http://lifepqv.com.br)

MANZINI, E; VEZZOLI, C. Design para a inovação social e sustentabilidade: comunidades criativas, organizações colaborativas e novas redes projetuais. Rio de Janeiro: E-papers, 2008.

MANZINI, E. Design: quando todos fazem design: uma introdução ao design para a inovação social; tradução de Luzia Araújo. São Leopoldo, RS: Ed. UNISINOS, 2017.

POWTOON. Storyboard. In: Powtoon, 2017. (http://www.powtoon.com/storyboard)

STICKDORN, M; SCHNEIDER, J. Isto é design thinking de serviços. Porto Alegre: Bookman, 2014.

SUNYATA. Sunyata qualidade de vida. In: Sunyata Qualidade de Vida, 2017. (http://www.sunyataqualidadedevida.com.br)

VERÃO RIO O GLOBO. Verão Rio. In: Facebook, 2017. (http://www.facebook.com/veraoriooglobo/)

VIDA EM FORMA. Gestão em saúde ocupacional. In: Vida em Forma, 2017. (http://www.vidaemforma.com.br) 